\title{
Analysing cyclist behaviour at cycling facility discontinuities using video data
}

\author{
Matin S. Nabavi Niaki ${ }^{a}$, Nicolas Saunier ${ }^{b}$, Luis F. Miranda-Moreno ${ }^{c}$ \\ ${ }^{a}$ PhD Candidate, Ecole Polytechnique de Montreal, 2900 Boulevard Edouard-Montpetit, Montreal H3T 1J4, Canada \\ ${ }^{b}$ Associate professor, Ecole Polytechnique de Montreal, 2900 Boulevard Edouard-Montpetit, Montreal H3T 1J4, Canada \\ 'Associate professor, McGill University, 817 Sherbrooke Street West, Montreal H3A 2K6, Canada
}

International Co-operation on

Theories and Concepts in Traffic Safety

This paper was presented at ICTCT workshop.

ABSTRACT: The primary purpose of any transportation network is to provide connectivity between the origin and travel destination. However, given the vehicle oriented structure of the road network in many countries, there are connectivity issues in the cycling network, which has been implemented later. Discontinuities are physical interruptions in the cycling network where cyclists are faced with unexpected situations such as the end of a cycling facility or the change from one facility type to another that are perceived as inconvenient and less safe. The microscopic behaviour of cyclists and the risks they face at these points of discontinuity has not been extensively investigated in the literature. This study aims to evaluate the challenges faced by cyclists at discontinuities by observing cyclist behaviour at these locations and comparing them to control sites using automated video analysis techniques. Our methodology allows the extraction of valuable microscopic data for evaluation of cyclist behaviour at any location. The methodology is applied to a case study of four sites in Montreal, Canada.

Using a set of discontinuity measures proposed in a previous work and applied to Montreal's cycling network, video data was collected from a pole-mounted camera at locations with discontinuity and control sites. After extracting road user trajectories from the video data, a trajectory clustering algorithm was applied to find cyclists' motion patterns and the various maneuver strategies adopted by cyclists. Speeds and acceleration statistics are extracted and compared between different motion patterns and between discontinuity and control sites. Results show that cyclists undertake a larger number of maneuvers at points of discontinuity compared to their control sites, and that both cyclist accelerations and speeds exhibit larger variations at discontinuities compared to larger and more stable speeds at control sites.
KEYWORDS: Cyclist behaviour, discontinuity, motion pattern learning, video analysis, speed analysis, trajectory clustering

\section{INTRODUCTION}

Given its many environmental and social benefits, cities are encouraging cycling as an affordable mode of transportation and are investing in expanding bicycle infrastructure. However, especially in North America, there is only a fraction of individuals who cycle either to commute or for recreational purposes (NHTSA \& National Household Traffic Survey of America, 2013; U.S. Department of Transportation, 2001). To increase the cycling mode share, cyclists' needs must be recognized and considered for further development of the road and cycling network. The preference of cyclists for dedicated cycling infrastructure like bike lanes, physically separated bike paths or bike boxes has been clearly established in recent research, as well as their positive impact on safety (Lusk, Morency, Miranda-Moreno, Willett, \& Dennerlein, 2013; Zangenehpour, Miranda-Moreno, \& Saunier, 2013). Accordingly, cities around the world are building more cycling infrastructure, increasing the length of the cycling network every year. This leads to easily quantifiable targets and announcements by city officials, e.g. $57 \mathrm{~km}$ of new cycle lanes or paths in Montreal for 2016-2017.

Despite the development of cycling networks, issues remain at specific locations creating discontinuities or interruptions in cycling trips. Road network connectivity is a given for automobiles, however, lack of connectivity is a critical factor in potential and actual bicycle use (Mekuria, Furth, \& Nixon, 2012). Countries where private vehicles are the dominant 
mode of transportation lack a traffic system that is responsive to the needs of cyclists. Implementing a cycling network on the existing vehicle-oriented road networks leads to discontinuities in the cycling network. These discontinuities include the sudden end of cycling facilities, unexpected changes from one cycling facility type to another, or cycling facility changes from one side of the road to the other. While discontinuities are considered in practice, for example when building new facilities or improving existing ones (CROW Fietsberaad, n.d.), only recently has a methodology to identify and quantify discontinuity measures been proposed and applied in a case study in Montreal (Nabavi-Niaki, Saunier, \& Miranda-Moreno, 2016).

Given the lack of quantifiable and objective measures of discontinuity, it is not surprising that little research has directly dealt with discontinuities in the cycling network and their impact on cyclists. Our study aims to close this gap by highlighting the effects of discontinuities on cyclist behaviour. The in-depth analysis of cyclist behaviour requires large amounts of microscopic data, i.e. road user trajectories at a fine temporal scale. To that end, our study applies computer vision techniques and trajectory clustering methods to video data, as done in a few past road user behaviour and safety studies (Laureshyn, Goede, Saunier, \& Fyhri, 2017; Mohamed \& Saunier, 2015; Saunier \& Sayed, 2006). This study makes use of video data to compare cyclist behaviour between sites with and without a discontinuity by automatically extracting road user trajectories from video data. The proposed methodology aims to identify and characterize the possible cyclist movements through trajectory clustering. The methodology is applied to a case study of four sites in Montreal, Canada.

The next section provides a background of studies investigating cyclist behaviour and their analysis methods. The proposed methodology is then described, followed by the descriptive analysis and discussion of results. The paper is summarised in the conclusion where limitations of this study and future works are presented.

\section{BACKGROUND}

\subsection{Factors Affecting Cyclist Behaviour}

To accommodate all cyclists with different comfort and experience levels, planners and policy makers must have an accurate understanding of the needs of all cyclists. Comfortable cycling requires smooth movement with the lowest possible energy input (Hölzel, Höchtl, \& Senner, 2012). Unless individuals can cycle to their destinations within a reasonable time and on a safe bike route without any stress or added effort, most of them will use a different mode of travel. Past studies have investigated and identified factors that affect cyclist behaviour in different situations, which can be categorised as infrastructural, traffic-related, environmental, and personal.

Infrastructural factors include the presence, type and dimensions of the cycling facility, the shoulder lane width, the pavement condition, and road grade. A study investigating infrastructural factors forecasted that the implementation of a physically separate cycling facility would increase the number of cyclists by $55 \%$ (Wardman, Tight, \& Page, 2007). Jensen studied the preference of cyclists for different cycling facility types through their perceived safety and found a range in the reported safety levels where cyclists felt most safe on cycle tracks (45\%), then less so with bike lanes (30\%) and even the least for shared streets $(10 \%)$. The variation in perceived safety among different cycling facility types implies that the points of change in cycling facility types constitute discontinuities in the cycling network (Jensen, Rosenkilde, \& Jensen, 2007). Studies have shown that cycling facility connectivity is linked with increased cycling (Broach, Dill, \& Gliebe, 2012; Sener, Eluru, \& Bhat, 2009; Mekuria et al., 2012). An initiative by the Dutch Cyclists' Association and the National Bicycle Platform Foundation (SFL) identified infrastructural barriers such as motorways, through roads, railway tracks and waterways as interruptions along a cycling facility (Brochure Dutch Cyclists' Association, 2003). Some proposed and implemented solutions to the inconveniences these interruptions pose include the construction of bicycle tunnels under major intersections with high speed and high volume vehicle traffic (CROW Fietsberaad, n.d.).

In the category of traffic-related factors, traffic volume and speed as well as the parking turnover and occupancy rates have been included in cyclist behaviour studies. Bernardi and Rupi found that the presence of pedestrian, vehicular traffic and heavy vehicles affects cyclist behaviour riding in mixed traffic (Bernardi \& Rupi, 2015). Another study found high speed limits, and street parking (high parking turnover and occupancy rate, and length of parking area) as factors 
affecting cyclist's route choice (Sener et al., 2009). Inexperienced, female and younger cyclists have indicated safety concerns when traveling alongside vehicular traffic (Garrard, Rose, \& Lo, 2008; Krizek \& Roland, 2005; Stinson \& Bhat, 2003). Vlakveld et al. found that cyclists in complex traffic situations (performing left turn at intersections) reduce their speed (Vlakveld et al., 2015).

Environmental factors associated with cycling include variables such as season, temperature, humidity and precipitation. Past studies show that the number of cyclists is reduced during colder or rainy conditions (Nosal \& Miranda-Moreno, 2014; Pucher $\&$ Buehler, 2006).

To attract and accommodate more cyclists, personal, including psychological, factors must also be considered. These factors include sensitivity to stress and safety, cycling experience level, age and gender. Several researchers have developed methods for qualitatively classifying road segments based on the level of stress experienced by cyclists (see (Bíl, Andrášik, \& Kubeček, 2015; Blanc \& Figliozzi, 2016; Harkey, 1998; Landis, 1994; Sorton \& Walsh., 1994)). A study found that the comfort of riding on dedicated cycling facilities may not compensate for the uncomfortable and high-stress points of discontinuity along the route (Mekuria et al., 2012). Studies have shown that cyclists make an effort to avoid stressful and less safe situations by choosing to add time and distance to their travel by choosing to travel on cycling facilities (Aultman-Hall, Hall, \& Baetz, 1997; Winters, Teschke, Grant, Setton, \& Brauer, 2010). Cyclist experience levels are linked to their comfort levels where more experienced cyclists are more comfortable compared to less experienced riders (Foster, Dill, \& Clifton, 2015; Harkey, 1998; Sorton \& Walsh., 1994). As noted in the traffic-related factors, less experienced, female and younger cyclists seem more sensitive to the proximity of vehicular traffic (Garrard et al., 2008; Krizek \& Roland, 2005; Stinson \& Bhat, 2003). For more experienced cyclists, discontinuities may be much less alarming (Willis, Manaugh, \& ElGeneidy, 2013), but for more concerned individuals, discontinuities are at best uncomfortable and may be an actual barrier to cycle (Nabavi-Niaki et al., 2016; Xie \& Levinson, 2007).

To combine several of these factors, Goodno et al. applied three different level of service (LOS) evaluation methods: the HCM Multimodal LOS (MMLOS), the Danish Bicycle LOS, and the Bicycle Environment Quality Index (BEQI), to evaluate the performance of a newly implemented cycling facility (Goodno, McNeil, Parks, \& Dock, 2013).

\subsection{Analysis Methods}

The challenges of studying cyclist behaviour are a result of their dynamic characteristics, including their movements, speed, acceleration and deceleration profiles, and their physical characteristics, including size, flexibility and capability (Twaddle, Schendzielorz, \& Fakler, 2014). One of the main challenges of analyzing cyclist behaviour is the lack of reliable data in sufficient quantities. Studying cyclist behaviour requires microscopic level extended and reliable trajectory data. However, despite the growing interest in cycling behaviour, few studies rely on microscopic data (trajectories) at specific sites.

Stated and revealed preference surveys as well as observational data have been widely used to study cyclist behaviour (Dill \& Gliebe, 2008; Hunt \& Abraham, 2007; Kang \& Fricker, 2013; Yang \& Mesbah, 2013). More recently GPS and video data are being used to gather more in depth information such as location, speed, trajectory and safety measures $(\mathrm{Li}$, Xiong, Li, Liu, \& Zhang, 2015; Ma \& Luo, 2016; Mereu, 2015; Zaki, Sayed, \& Cheung, 2013; Zangenehpour, Strauss, Miranda-Moreno, \& Saunier, 2016). Most of these studies extracted location and speed measurements manually from GPS or video data. However, manual data analysis is time consuming, not very accurate and prone to error. To overcome these problems, computer vision techniques have been used to extract precise spatial and temporal road user measurements in a more resource efficient manner (Ismail, Sayed, Saunier, \& Lim, 2010; B. T. Morris $\&$ Trivedi, 2008; Zaki et al., 2013; Zangenehpour et al., 2016). Challenges with this approach are caused by lighting variations, shadows, and groups of road users moving close to each other or occluding each other, which is more frequent if the camera angle is low (B. T. Morris \& Trivedi, 2008).

Once road user trajectories are obtained, they must be classified into different categories or road users. Methods range from simple statistics on the size of the road users in images, to methods combining different sources of information such as speed, appearance and location (Zangenehpour, MirandaMoreno, \& Saunier, 2015).

The next step is to interpret the cyclist trajectories. A common technique to explore and interpret complex datasets is clustering, i.e. the segmentation 
of the dataset into more homogeneous subsets. Several methods have been proposed for the particularly challenging problem of trajectory clustering or motion pattern learning as it is also called (B. T. Morris \& Trivedi, 2008). Because trajectories are multi-dimensional data structures of varying lengths, common distance or similarity measures like the Euclidean distance cannot be used directly. For that purpose, similarity measures used for sequences like DNA and handwriting have been adapted to spatial trajectories: the most flexible and accurate may be the longest common subsequence (LCSS) (B. Morris $\&$ Trivedi, 2009). Another challenge of clustering trajectories is the representation of each cluster (motion pattern): contrary to methods like k-means applied to fixed-length vectors, trajectories cannot be easily averaged. An original model and clustering algorithm based on the LCSS were proposed in (Saunier, Sayed, \& Lim, 2007) and refined in (Mohamed \& Saunier, 2015) where each cluster is represented by an actual trajectory and trajectories are assigned to the motion pattern cluster based on their highest similarity. Motion pattern learning was initially developed and applied to motion prediction to compute surrogate measures of safety like time to collision (Mohamed \& Saunier, 2015; Saunier et al., 2007).

\section{METHODOLOGY}

The methodology to study cyclist behaviour at discontinuities consists of five main steps, which are represented in the overview in Figure 1.

\subsection{Site Selection}

To identify sites with discontinuities in Montreal, Canada, the methodology presented in (Nabavi-Niaki et al., 2016) was applied (Figure 1, step 1). Discontinuity sites were selected based on type. To select control sites, locations along the same road near the discontinuity sites were selected with similar vehicle and bike flows. The locations of the four sites (two with a discontinuity and two controls) are shown in the second step of Figure 1.

\subsection{Video Data Collection and Processing}

A GoPro camera was used to record video at the four locations on weekdays in October 2015. Recording lasted on average seven hours, starting around
7:00 AM. The cameras were mounted on tall poles supported by an existing light pole to provide stability. The camera was placed in a position and at an angle to capture a good view of the area where cyclists would travel. Data was collected in temperatures between $16^{\circ} \mathrm{C}$ and $20^{\circ} \mathrm{C}$ and in mainly sunny and overcast conditions.

In the video recordings, three-dimensional objects are captured in a two-dimensional image space, where the image space, distances and angles are distorted. For analysis purposes, to obtain the road user trajectories in real-world coordinates rather than in pixels, the distortion of the video image caused by the camera lens is corrected, and the mapping process to convert coordinates in the image plane to world coordinates relies on a homography matrix.

Data preparation includes four sub-steps (Figure 1, step 4): road user feature detection, feature tracking, similar feature grouping based on common motion constraints, and road user classification into three road user types (vehicle, cyclist and pedestrian). These steps are performed using a feature-based tracker and a classification tool from the open-source project "Traffic Intelligence" (Jackson, MirandaMoreno, St-Aubin, \& Saunier, 2013). Tracking parameters are tuned through trial and error in this study to reduce over-segmentation where one road user is tracked as several objects, and over-grouping where many road users are grouped into one object. The classifier from (Zangenehpour et al., 2015) is used with the updated speed distribution parameters based on site observations. The results of this step are classified road user trajectories.

\subsection{Cyclist Behaviour Analysis}

The final step in the methodology (step 5) relies on the cluster model and clustering algorithm developed in previous work (Mohamed \& Saunier, 2015; Saunier \& Sayed, 2006). Each cluster is represented by an actual road user trajectory (the longest). The clustering algorithm is a variation on the principle of K-Means that trades the number of clusters for a minimum similarity between a motion pattern cluster and the trajectories assigned to it. The similarity depends on the LCSS, using the Manhattan distance ${ }^{1}$

1 The Manhattan distance is defined as the sum of the horizontal and vertical paths between two points in a grid network. For two points with coordinates $\left(x_{1}, y_{1}\right)$ and $\left(\mathrm{x}_{2}, \mathrm{y}_{2}\right)$, their Manhattan distance is $\left|\mathrm{x}_{1}-\mathrm{x}_{2}\right|+\left|\mathrm{y}_{1}-\mathrm{y}_{2}\right|$. 


\section{Identify \\ discontinuities along \\ cycling facility}

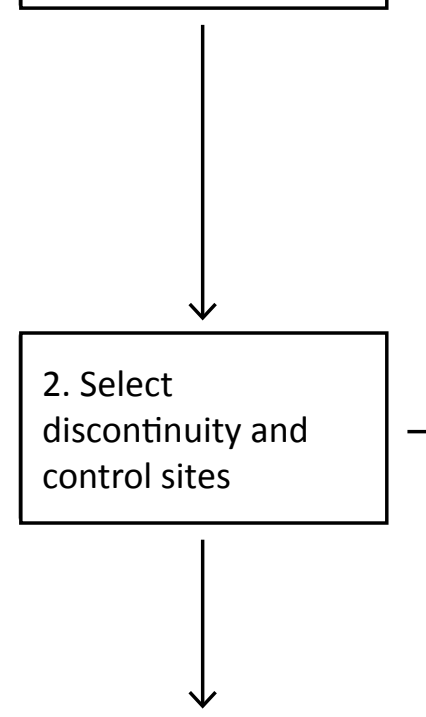

3. Video data
collection
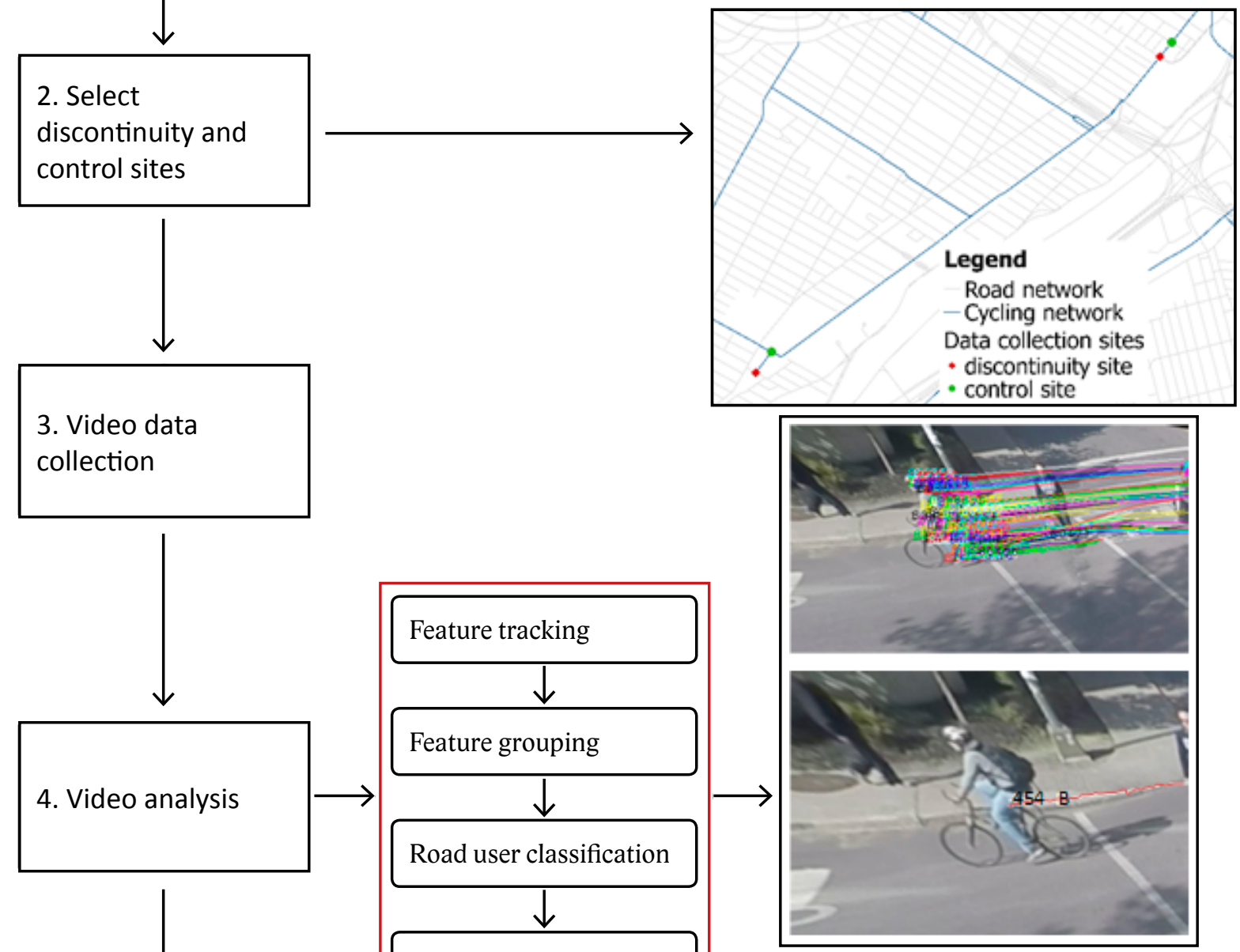

Trajectory clustering
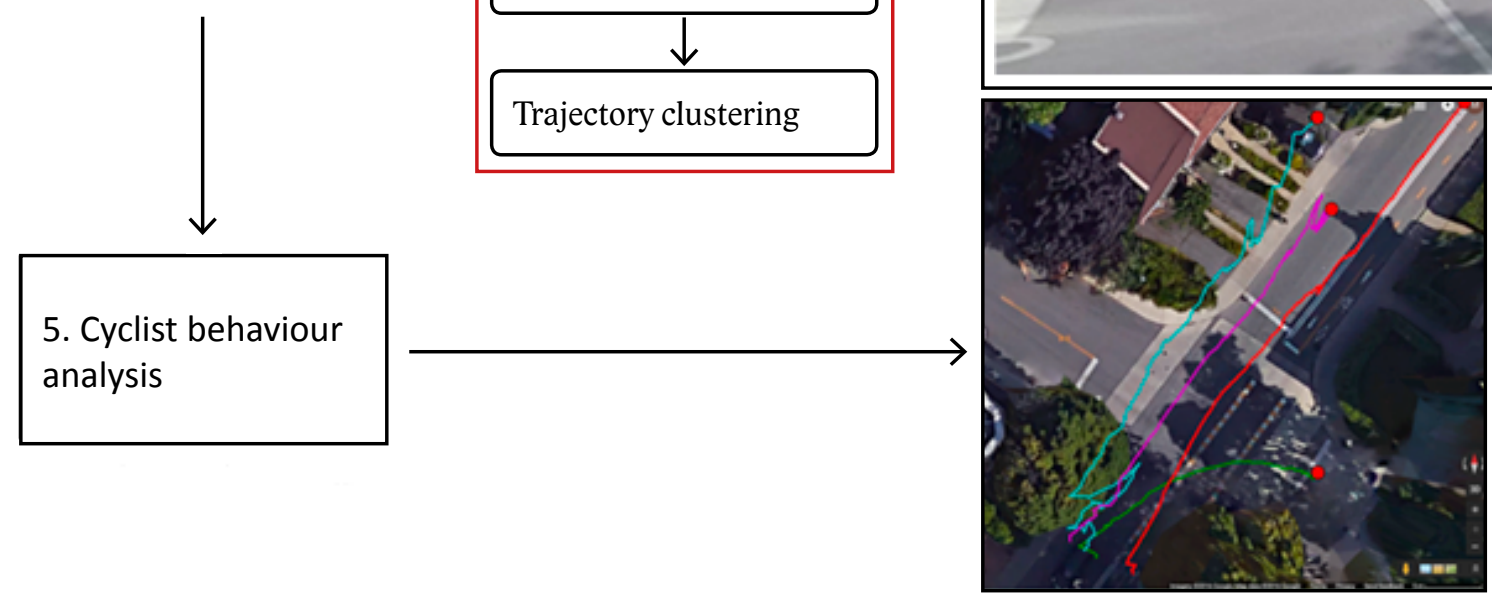

Figure 1. Speed profiles for "ideal" interactions when the driver gives way to the pedestrian well in advance (Várhelyi, 1998). 
and a threshold to define similar individual positions, and on normalizing the similarity (the number of similar points) by the minimum length of the two trajectories (the reader is referred to (Saunier et al., 2007) for the details). When a trajectory is not similar enough to current clusters, it becomes the prototype of a new cluster. The algorithm therefore has two parameters, the maximum distance for the Manhattan distance and the minimum similarity to assign trajectories to clusters: in this study, they are set to $2 \mathrm{~m}$ and 0.6 respectively. To generate higher quality clusters, each road user is represented by its longest feature trajectory instead of the average feature trajectory, which can be very noisy. The result of the algorithm is a set of clusters or motion patterns, where each motion pattern is represented by a real (prototype) trajectory and all the road user trajectories are assigned to a motion pattern (the one with the most similar prototype).

Only the cyclist trajectories potentially affected by the discontinuity are considered in the analysis. These are the trajectories with the same origin and destination as the trajectories that would have used the cycling facility if it was continuous, e.g. in the control site. The analysis relies on the motion patterns that contain the cyclist trajectories with the identified origin-destination.

To characterize the dynamics of cyclist movements, several statistics are extracted from each cyclist speed and acceleration time series (acceleration is computed using the Savitzky-Golay filter with polynomial order 1 and window length 9): the median, $85^{\text {th }}$ centile, $15^{\text {th }}$ centile, and the standard deviation. Each motion pattern is then characterized by the mean of each speed statistic.

\section{EXPERIMENTAL RESULTS FOR CYCLIST BEHAVIOUR}

\subsection{Site Description}

The locations of the selected sites are shown in the second step of Figure 1. Four sites were selected, two with discontinuities and two control sites. Selected sites were T- or four leg intersections with bidirectional physically separated cycle tracks. Table 1 presents the sites with information such as description of discontinuity and traffic control devices for vehicles and bikes. Two different discontinuity types were selected: change of facility side from one side of the street to the other side, and change in facil- ity type from separate cycle track to shared roadway (Table 1).

The motion patterns are presented in Figures 2 and 3. Each figure shows the direction of the road with a grey arrow and the direction of the cycling facility with thin white arrows. As observed in the figures, the actual trajectory locations may be slightly shifted because of perspective when projecting the image coordinates to the ground plane on the aerial images. The point at the beginning of each trajectory represents the starting point of the trajectory, i.e. the first detected position. The colour gradient is representative of the proportion of the number of cyclists in the cluster to the total number of cyclists going through the intersection for the same origin-destination, from yellow for a low proportion to red for high proportions of cyclists (with orange in between). The number of cyclists per motion pattern as well as their proportion for the same origin-destination are presented in tables 2 and 3 .

\subsection{Change in Cycling Facility Type}

\subsubsection{Motion Patterns}

The discontinuity at Coffee St and Elmhurst Ave is the change from a separate cycle track on Coffee to a designated roadway on the south leg of Elmhurst Ave and no facility on the north leg of Elmhurst Ave (Figure 2.a). At this T-intersection, not only do left turning cyclists at the end of the separate cycle track turn into a shared lane with vehicles, they have no option but to cross a two-lane road to continue their journey (unless they turn left into the sidewalk which is prohibited for cyclists to ride in). As expected, cyclists performed distinctively different movements at the discontinuity site, split into three motion patterns (Figure 2.a). The results show that at this discontinuity, $64 \%$ of the left-turning cyclists travel to the far side of the road (motion pattern 2 in Figure 2.a) to distance themselves from vehicles on the road. Furthermore, $28 \%$ of cyclists turn immediately into the sidewalk (motion pattern 3 in Figure 2.a), which is prohibited in Canada (the trajectory seems to correspond to cyclists on the road, while looking through the videos shows that in fact they were traveling on the sidewalk). The last $8 \%$ of cyclists make a vehicular left turn maneuver and merge with traffic, traveling on the road (motion pattern 1 in Figure 2.a). The control site at Coffee and West Broadway St has the same cycle track running on Coffee St, and another cycle track on the southeast 
Table 1 Site description

\begin{tabular}{|c|c|c|c|}
\hline $\begin{array}{l}\text { Discontinuity } \\
\text { Location }\end{array}$ & Discontinuity Site Description & $\begin{array}{l}\text { Control } \\
\text { Location }\end{array}$ & Control Site Description \\
\hline \multirow{9}{*}{$\begin{array}{l}\text { Coffee } \\
\text { \& Elmhurst } \\
\text { (Figure 2.a) }\end{array}$} & Discontinuity: facility type change & \multirow{9}{*}{$\begin{array}{l}\text { Coffee } \\
\text { \& West } \\
\text { Broadway } \\
\text { (Figure 2.b) }\end{array}$} & Control site \\
\hline & T-intersection & & T-intersection \\
\hline & Bi-directional separate cycle track on Coffee & & Bi-directional separate cycle track on Coffee \\
\hline & $\begin{array}{l}\text { St changing to a shared roadway at Elmhurst } \\
\text { Ave }\end{array}$ & & St and southeast leg of West Broadway Stw \\
\hline & $\begin{array}{l}\text { Origin-destination of movements affected by } \\
\text { discontinuity: left turn NE to SE }\end{array}$ & & $\begin{array}{l}\text { Comparable origin-destination: left turn NE } \\
\text { to SE }\end{array}$ \\
\hline & Stop sign for cyclists on Coffee St & & Stop sign on Coffee St \\
\hline & Uncontrolled for vehicles & & \\
\hline & $\begin{array}{l}\text { Coffee is a one-way street allowing northwest } \\
\text { movements for vehicles }\end{array}$ & & $\begin{array}{l}\text { Coffee is a one-way street allowing northwest } \\
\text { movements for vehicles }\end{array}$ \\
\hline & Elmhurst is a two-way street & & West Broadway is a one-way street \\
\hline \multirow{5}{*}{$\begin{array}{l}\text { Maisonneuve } \\
\text { \& Ste.- } \\
\text { Catherine } \\
\text { (Figure 3.a) }\end{array}$} & Discontinuity: facility side change & \multirow{5}{*}{$\begin{array}{l}\text { Maisonneuve } \\
\text { \& Prince } \\
\text { Albert } \\
\text { (Figure 3.b) }\end{array}$} & Control site \\
\hline & $\begin{array}{l}\text { Bi-directional separate cycle track located on } \\
\text { the south side of Maisonneuve Blvd, east of } \\
\text { Ste.-Catherine St changing to the north side of } \\
\text { Maisonneuve Blvd, west of Ste.-Catherine St }\end{array}$ & & $\begin{array}{l}\text { Bi-directional separate cycle track located on } \\
\text { the south side of Maisonneuve Blvd }\end{array}$ \\
\hline & $\begin{array}{l}\text { Origin-destination of movements affected by } \\
\text { discontinuity: straight movements towards } \\
\text { NE or SW }\end{array}$ & & $\begin{array}{l}\text { Comparable origin-destination: straight } \\
\text { movements towards NE or SW }\end{array}$ \\
\hline & $\begin{array}{l}\text { Maisonneuve is a one-way street allowing } \\
\text { southwest movements east of Ste.-Catherine } \\
\text { St changing to a bi-directional street west of } \\
\text { Ste.-Catherine St }\end{array}$ & & $\begin{array}{l}\text { Maisonneuve is a one-way street allowing } \\
\text { southwest movements }\end{array}$ \\
\hline & $\begin{array}{l}\text { Signalized intersection, includes all- } \\
\text { pedestrian phase }\end{array}$ & & All-way stop controlled intersection \\
\hline
\end{tabular}

leg of West Broadway St as well as a bike lane on the northeast leg of the intersection (Figure 2.b) (the cycling facility on West Broadway is not visible due to the aerial view trees blocking the view, however the location of the facility is manually added). Also, West Broadway is a one-way road, eliminating the stress of crossing two lanes with vehicles coming from both directions which is the case at the discontinuity. These factors eliminate the problem from the discontinuity and allow cyclists to turn directly into the cycle track without being disturbed by vehicular traffic from the opposite direction (motion pattern 1 in Figure 2.b).

Regarding the other cyclist movement, the right turn from SE to NE (cyclists traveling northwest on Elmhurst and turning right into Coffee and cyclists on
West Broadway St traveling southwest and turning right into Coffee), no difference was found with only one motion pattern at both sites (motion pattern 4 in Figure 2.a and motion pattern 2 in Figure 2.b). In particular, the right turn at the discontinuity site is simpler since the cyclist movement does not conflict with any vehicular movement).

\subsubsection{Speed and Acceleration}

At the discontinuity site, the trajectories belonging to each motion pattern have lower median speeds compared to the control site (Table 2). Cyclists crossing the bi-directional road at the end of the separate cycling facility into the shared roadway decelerate and have lower speeds, which is associated with more ma- 


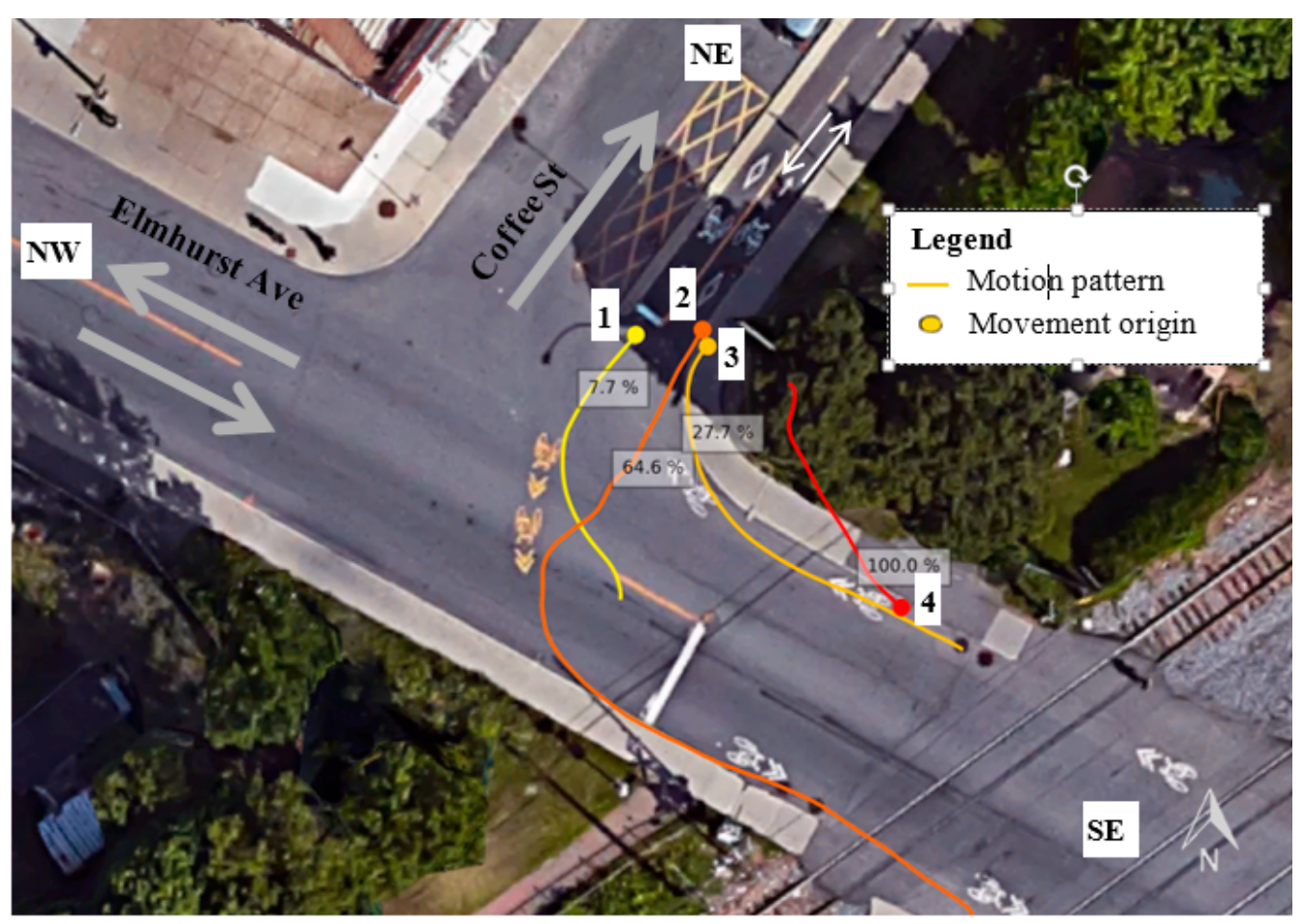

\section{a. Coffee St and Elmhurst Ave (discontinuity)}

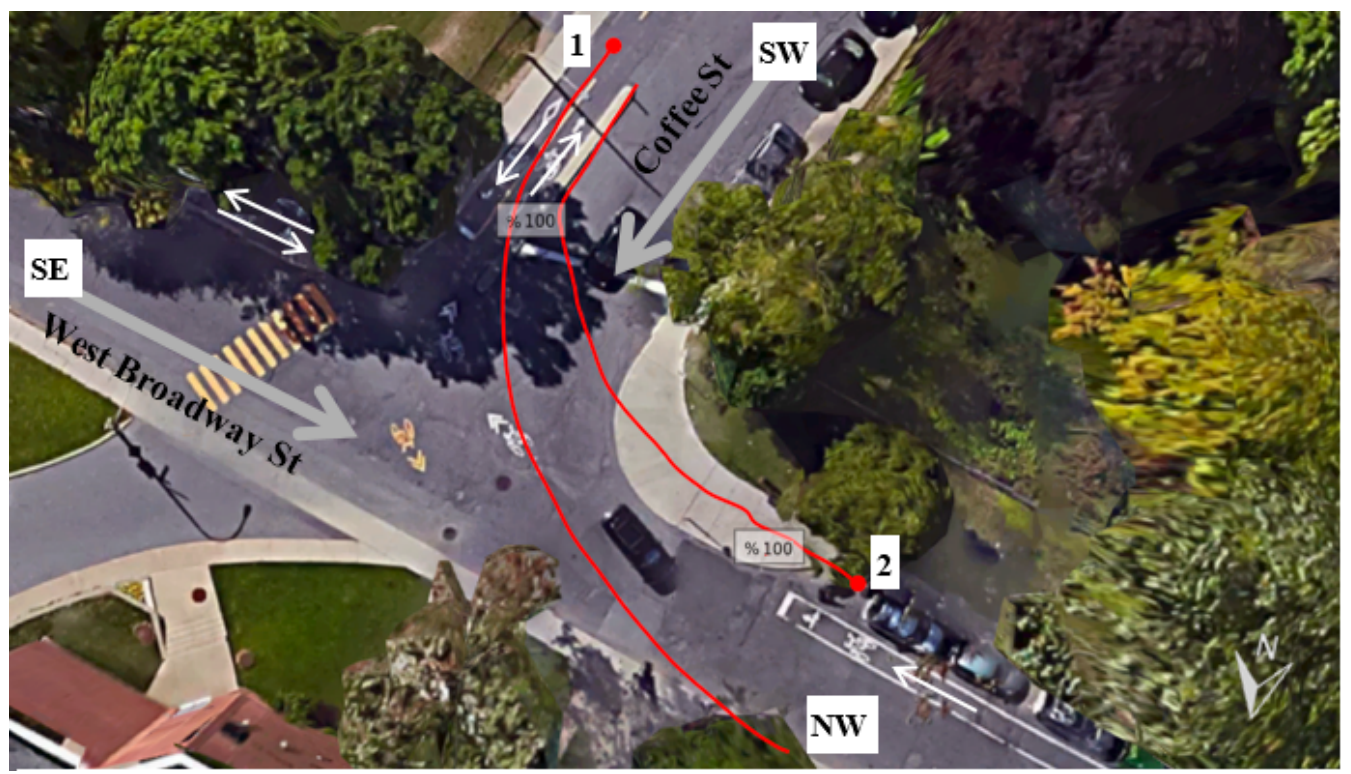

b. Coffee St and West Broadway St (control)

Figure 2: Cyclist motion patterns (represented by their prototype trajectories) for the change in cycling facility type discontinuity

neuvers, e.g. braking, and which may be to feel safer. On the other hand, motion pattern 3 has similar mean speed to the control site since cyclists are turning left onto the sidewalk avoiding any interaction with vehicles, while having the largest $85^{\text {th }}$ speed centile and decelerating more strongly since they are entering a space shared with pedestrians (which is not allowed in Canada). Comparing the mean of speed standard deviations shows that there is more variability in the speeds of cyclists within each motion pattern at the discontinuity especially when sharing space with vehicles compared to the control site. Acceleration analysis statistics are also presented in Table 2. For the left turn, the speed and acceleration variations are mostly higher at the discontinuity location (Coffee and Elmhurst). 
Table 2 Speed and acceleration statistics at the discontinuity and control sites (the most extreme values between the discontinuity and control sites are highlighted in bold)

\begin{tabular}{|c|c|c|c|c|c|c|c|c|c|c|c|}
\hline \multicolumn{4}{|c|}{ Description } & \multicolumn{4}{|c|}{ Speed statistics } & \multicolumn{4}{|c|}{ Acceleration statistics } \\
\hline 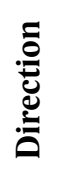 & Location & $\begin{array}{l}\text { Motion } \\
\text { pattern } \\
\text { number }\end{array}$ & $\begin{array}{l}\text { Number } \\
\text { of cyclists } \\
\text { in motion } \\
\text { pattern }\end{array}$ & $\begin{array}{l}\text { Mean of } \\
\text { median } \\
\text { speeds } \\
(\mathrm{m} / \mathrm{s})\end{array}$ & $\begin{array}{l}\text { Mean } \\
\text { of 85th } \\
\text { centile } \\
(\mathrm{m} / \mathrm{s})\end{array}$ & $\begin{array}{l}\text { Mean } \\
\text { of } 15 \text { th } \\
\text { centile } \\
(\mathrm{m} / \mathrm{s})\end{array}$ & $\begin{array}{l}\text { Mean } \\
\text { of St. } \\
\text { Dev. } \\
(\mathrm{m} / \mathrm{s})\end{array}$ & $\begin{array}{l}\text { Mean of } \\
\text { median } \\
\text { acceleration } \\
\left(\mathrm{m} / \mathrm{s}^{2}\right)\end{array}$ & $\begin{array}{l}\text { Mean } \\
\text { of } 85 \text { th } \\
\text { centile } \\
\left(\mathrm{m} / \mathrm{s}^{2}\right)\end{array}$ & $\begin{array}{l}\text { Mean } \\
\text { of } 15 \text { th } \\
\text { centile } \\
\left(\mathrm{m} / \mathrm{s}^{2}\right)\end{array}$ & $\begin{array}{l}\text { Mean } \\
\text { of St. } \\
\text { Dev. } \\
\left(\mathrm{m} / \mathrm{s}^{2}\right)\end{array}$ \\
\hline \multirow{4}{*}{ 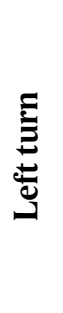 } & $\begin{array}{l}\text { Coffee \& West } \\
\text { Broadway } \\
\text { (control site) }\end{array}$ & 1 & $62(100 \%)$ & 15.6 & 17.2 & 14.2 & 1.7 & 0.01 & 0.20 & -0.14 & 0.24 \\
\hline & \multirow{3}{*}{$\begin{array}{l}\text { Coffee } \\
\& \text { Elmhurst } \\
\text { (discontinuity } \\
\text { site) }\end{array}$} & 1 & $5(7.7 \%)$ & 14.4 & 18.2 & 10.2 & 3.6 & -0.06 & 0.09 & -0.22 & 0.17 \\
\hline & & 2 & $42(64.6 \%)$ & 13.6 & 18.5 & 9.5 & 4.1 & -0.05 & 0.41 & -0.51 & 0.46 \\
\hline & & 3 & $18(27.7 \%)$ & 15.6 & 18.8 & 12.9 & 2.8 & -0.07 & 0.36 & -0.36 & 0.40 \\
\hline \multirow{2}{*}{ 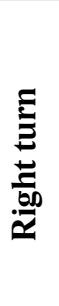 } & $\begin{array}{l}\text { Coffee \& West } \\
\text { Broadway } \\
\text { (control site) }\end{array}$ & 2 & $3(100 \%)$ & 16.5 & 18.3 & 14.6 & 2.2 & 0.01 & 0.27 & -0.22 & 0.33 \\
\hline & $\begin{array}{l}\text { Coffee } \\
\text { \& Elmhurst } \\
\text { (discontinuity } \\
\text { site) }\end{array}$ & 4 & $3(100 \%)$ & 9.8 & 11.4 & 8.6 & 1.7 & 0.00 & 0.24 & -0.21 & 0.32 \\
\hline
\end{tabular}

\subsection{Change in Facility Side}

\subsubsection{Motion patterns}

In this category, the discontinuity site is Maisonneuve Blvd west and Sainte-Catherine St where the separate cycle track located on the southeast side of Maisonneuve Blvd is moved to the north side of the road on the west side of the intersection (Figure 3.a). The aerial image of the intersection is not up to date and does not show the recently implemented cycle track on the west leg of Maisonneuve Blvd as manually indicated with white arrows.

As observed from the clustering results, cyclists traveling northeast have made four distinctive movements to cross the intersection: motion patterns 1 to 4 in Figure 3.a. Three movements are initiated from inside and one from outside the cycle track: $53 \%$ of cyclists cross the west side crosswalk, then steer right to enter the cycle track, corresponding to motion pattern 1 in Figure 3.a, $16 \%$ of cyclists cross the east side crosswalk and turn left into the facility, corresponding to motion pattern 2 in Figure 3.a, $6 \%$ of cyclists travel straight on Maisonneuve Blvd towards oncoming traffic on the left side of the road and steer right to enter the cycle track further down the road, corresponding to motion pattern 3 in Figure 3.a, and the final $25 \%$ of cyclists travel from the right side of the road and not from the cycling facility to be able to continue straight into the cycling facility, corre- sponding to motion pattern 4 in Figure 3.a. On the other hand, in the control intersection, all cyclists travel northeast through the intersection using the cycle track (motion pattern 1 in Figure 3.b).

Movements in the opposite direction follow a similar distribution; cyclists traveling southwest made four different movements to cross the intersection at the discontinuity. $62 \%$ of cyclists travel from outside of the facility on the northeast sidewalk (which is prohibited in Canada) straight into the facility, corresponding to motion pattern 5 in Figure 3.a. Among cyclists traveling from outside of the facility, $9 \%$ merge with traffic to cross the intersection and enter the cycle track, corresponding to motion pattern 6 in Figure 3.a. Initiating from inside the cycle track, $19 \%$ of cyclists travel diagonally into the cycling facility on the opposite side, corresponding to motion pattern 7 in Figure 3.a. The final $10 \%$ of cyclists immediately turn right to cross the northeast crosswalk and then turn left to cross the northwest crosswalk and enter the cycle track, corresponding to motion pattern 8 in Figure 3.a. At the control site, all cyclists travel northeast on Maisonneuve Blvd through the intersection using the facility, corresponding to motion pattern 2 in Figure 3.b.

\subsubsection{Speed and Acceleration}

As presented in Table 3, cyclists travelling in the control site generally have higher median speeds com- 


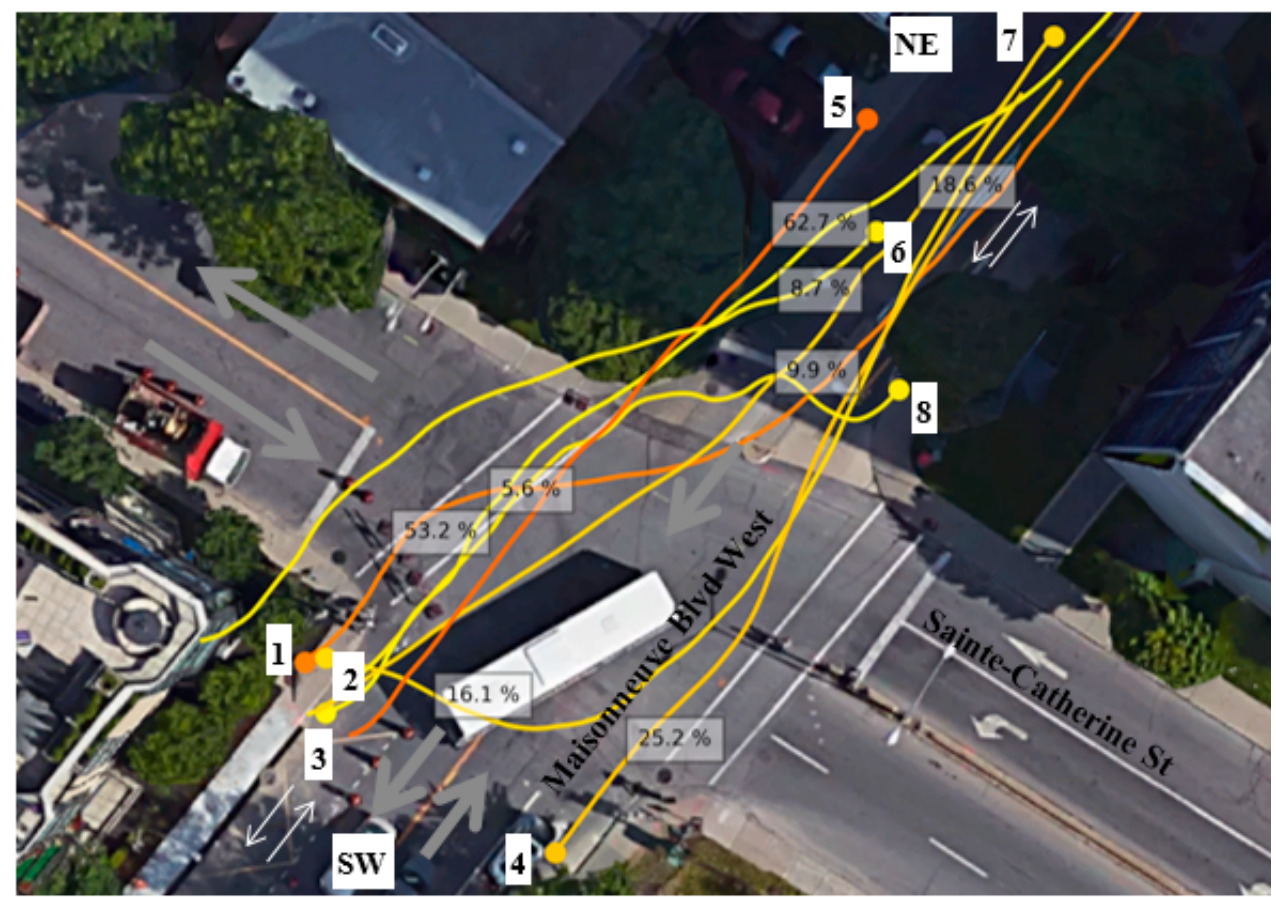

\section{a. Maisonneuve Blvd and Sainte-Catherine St (discontinuity)}

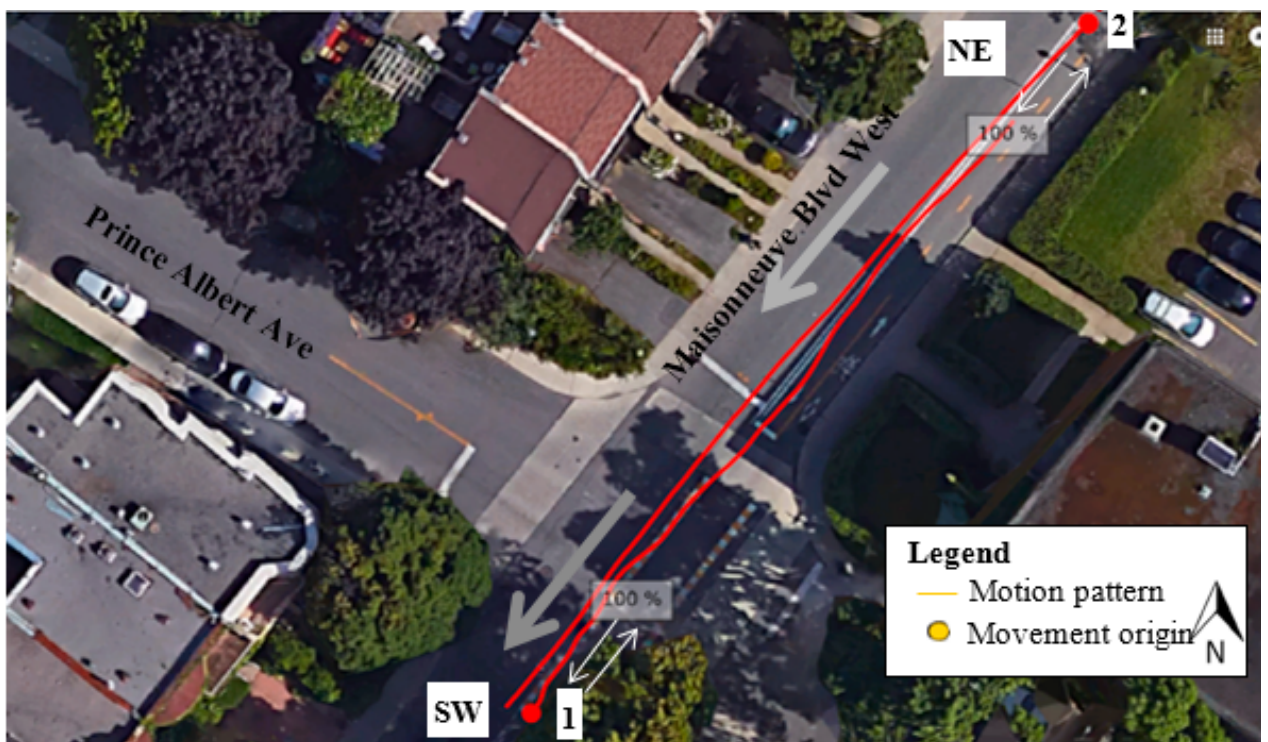

b. Maisonneuve Blvd west and Prince Albert Ave (control)

Figure 3 Cyclist motion patterns (represented by their prototype trajectories) for the change in cycling facility side discontinuity

pared to the discontinuity site Maisonneuve Blvd and Ste.-Catherine St. While there is variation between motion patterns, cyclists in the discontinuity site also show a higher variation in speed and acceleration (measured by higher mean of $85^{\text {th }}$ centiles of speed and acceleration and lower $15^{\text {th }}$ centiles of speed and acceleration) compared to the control site. Acceleration statistics in Table 3 show that cyclists perform harsher accelerations or decelerations at the discon- tinuity as they face more complex tasks and must undertake more complex maneuvers.

\section{DISCUSSION}

For the change in cycling facility type (Coffee St Elmhurst Ave, compared to Coffee St - West Broadway St), comparing the left turns at the discontinuity 
Table 3 Speed and acceleration statistics at the discontinuity and control sites (the most extreme values between the discontinuity and control site per direction are highlighted in bold)

\begin{tabular}{|c|c|c|c|c|c|c|c|c|c|c|c|}
\hline \multicolumn{4}{|c|}{ Description } & \multicolumn{4}{|c|}{ Speed statistics } & \multicolumn{4}{|c|}{ Acceleration statistics } \\
\hline 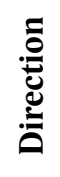 & Location & $\begin{array}{l}\text { Motion } \\
\text { pattern } \\
\text { number }\end{array}$ & $\begin{array}{l}\text { Number } \\
\text { of cyclists } \\
\text { in motion } \\
\text { pattern }\end{array}$ & $\begin{array}{l}\text { Mean of } \\
\text { median } \\
\text { speeds } \\
(\mathrm{m} / \mathrm{s})\end{array}$ & $\begin{array}{l}\text { Mean } \\
\text { of 85th } \\
\text { centile } \\
(\mathrm{m} / \mathrm{s})\end{array}$ & $\begin{array}{l}\text { Mean } \\
\text { of } 15 \text { th } \\
\text { centile } \\
(\mathrm{m} / \mathrm{s})\end{array}$ & $\begin{array}{l}\text { Mean } \\
\text { of St. } \\
\text { Dev. } \\
(\mathrm{m} / \mathrm{s})\end{array}$ & $\begin{array}{l}\text { Mean of } \\
\text { median } \\
\text { acceleration } \\
\left(\mathrm{m} / \mathrm{s}^{2}\right)\end{array}$ & $\begin{array}{l}\text { Mean } \\
\text { of } 85 \text { th } \\
\text { centile } \\
\left(\mathrm{m} / \mathrm{s}^{2}\right)\end{array}$ & $\begin{array}{l}\text { Mean } \\
\text { of } 15 \text { th } \\
\text { centile } \\
\left(\mathrm{m} / \mathrm{s}^{2}\right)\end{array}$ & $\begin{array}{l}\text { Mean } \\
\text { of St. } \\
\text { Dev. } \\
\left(\mathrm{m} / \mathrm{s}^{2}\right)\end{array}$ \\
\hline \multirow{5}{*}{ 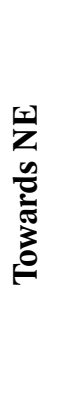 } & $\begin{array}{l}\text { Maisonneuve } \\
\text { \& Prince } \\
\text { Albert } \\
\text { (control site) }\end{array}$ & 1 & $493(100 \%)$ & 22.0 & 24.8 & 19.8 & 2.6 & -0.01 & 0.22 & -0.23 & 0.29 \\
\hline & \multirow{4}{*}{$\begin{array}{l}\text { Maisonneuve } \\
\text { \& Ste.- } \\
\text { Catherine } \\
\text { (discontinuity) }\end{array}$} & 1 & $268(53.2 \%)$ & 18.9 & 22.5 & 14.7 & 5.0 & 0.03 & 0.23 & -0.20 & 0.41 \\
\hline & & 2 & $81(16.1 \%)$ & 20.4 & 25.3 & 17.5 & 3.9 & 0.02 & 0.47 & -0.19 & 0.39 \\
\hline & & 3 & $28(5.6 \%)$ & 21.7 & 25.8 & 19.1 & 4.9 & 0.00 & 0.26 & -0.23 & 0.44 \\
\hline & & 4 & $127(25.2 \%)$ & 20.2 & 24.3 & 16.9 & 4.0 & 0.04 & 0.26 & -0.15 & 0.31 \\
\hline \multirow{5}{*}{ 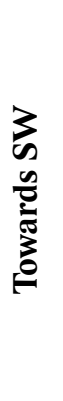 } & $\begin{array}{l}\text { Maisonneuve } \\
\text { \& Prince } \\
\text { Albert } \\
\text { (control site) }\end{array}$ & 2 & $149(100 \%)$ & 21.6 & 24.5 & 19.0 & 2.8 & 0.01 & 0.21 & -0.20 & 0.26 \\
\hline & \multirow{4}{*}{$\begin{array}{l}\text { Maisonneuve } \\
\text { \& Ste.- } \\
\text { Catherine } \\
\text { (discontinuity) }\end{array}$} & 5 & $101(62.7 \%)$ & 21.4 & 25.9 & 16.6 & 4.3 & 0.06 & 0.26 & -0.12 & 0.26 \\
\hline & & 6 & $14(8.7 \%)$ & 21.0 & 23.3 & 17.3 & 3.0 & 0.01 & 0.20 & -0.13 & 0.26 \\
\hline & & 7 & $30(18.6 \%)$ & 19.4 & 24.4 & 14.7 & 4.6 & 0.07 & 0.39 & -0.15 & 0.29 \\
\hline & & 8 & $16(9.9 \%)$ & 14.9 & 18.5 & 10.4 & 3.9 & 0.04 & 0.20 & -0.09 & 0.21 \\
\hline
\end{tabular}

and control locations shows that for the three movements through the discontinuity, one movement was observed in the control site (Figure 2.a motion patterns 1, 2 and 3 versus Figure 2.b motion pattern 1). This shows that cyclists react differently and with more varied strategies at the discontinuity. The same observation is made at the discontinuity site with change in cycling facility side (Maisonneuve West Blvd - SainteCatherine St, compared to Maisonneuve West Blvd Prince Albert Ave). While there is one movement for cyclists traveling either northeast or southwest at the control site, four different movements were observed at the discontinuity: Figure 3.b, motion patterns 1 and 2 versus Figure 3.a, motion patterns 1 through 8 . The discontinuity also forces cyclists out of the cycle track before they approach the intersection (motion patterns 4 and 5 in Figure 3.a) so they can travel straight to the other side of the intersection to enter the cycling facility. At discontinuities, cyclists may not know how to proceed and may contemplate different movements from which they choose automatically or consciously depending on their comfort levels, skills and experience. The results of this study are consistent with past findings showing that cyclists behave differently by adopting different left-turning maneuvers at intersections
(Copenhagenize Design Co., 2013; Twaddle, 2017), cyclists with different experience levels have different preferences (Dill \& Gliebe, 2008; Geller, 2009), and cyclists belonging to different age and gender groups have different observed behaviours at an intersection bicycle box (Zangenehpour et al., 2013).

Another behaviour is observed where cyclists choose to travel outside of the cycle track and ride on the sidewalk (motion pattern 3 in Figure 2.a, and motion pattern 5 in Figure 3.a.), which is prohibited in Canada. This may be an indication of the cyclists' difficult choices at discontinuities. Studies have found that cyclists prefer riding on cycling facilities compared to sidewalks where the space is shared with pedestrians (Aultman-Hall \& Adams, 1998; Srisurapanon et al., 2003). Choosing to ride on the sidewalk would therefore show that the discontinuity is a more important factor for some cyclists than the availability of a cycling facility.

Assuming cyclists with similar personal characteristics travel through sites with a discontinuity and control sites, the observed differences may be attributed to infrastructure and traffic-related differences. Although the main difference between the sites was the discontinuity, other factors may also play a role. 
One needs to investigate these other factors that may result in the distinct movements at these locations, which requires data from more locations and other means of analysis.

Speed and acceleration statistics were extracted from all trajectories and summarized for each motion pattern. Like movement variations, cyclists also had larger variations in speed, acceleration and deceleration at discontinuities compared to the control sites, which may be related to the behaviour of cyclists with different experience levels (see (Vlakveld et al., 2015) for speed behaviour in different age groups). Aside from the variation, the highest acceleration and decelerations at each of the four locations were observed at discontinuities. These variations support the fact that discontinuities are locations where cyclists are unsure of the path they should take to safely continue their journey.

It also suggests that other road users are also affected by discontinuities. Vehicles and pedestrians face unexpected movements and large variations in speeds from cyclists at these sites, compared to sites without discontinuities where cyclist speeds and movements are more predictable.

\section{CONCLUSION}

Although many studies have considered cyclist behaviour in different situations and conditions, there have been no in-depth microscopic evaluation of the effects of discontinuities on cyclist behaviour. This paper makes use of video data and computer vision techniques to obtain cyclist trajectories at points of discontinuity and trajectory clustering to study cyclist behaviour.

The use of cyclist trajectory clustering provided valuable information on the microscopic movements of cyclists. This approach allowed us to distinguish several motion patterns. Studying two types of discontinuities in the cycling network in Montreal: Coffee St and Elmhurst St (Figure 2.a), and Maisonneuve Blvd and Sainte-Catherine St (Figure 3.a), showed that cyclists chose between a larger set of movements compared to one single movement at their control sites. Higher variations in speed, acceleration and deceleration are observed at discontinuity locations which indicates that cyclists with different comfort levels adjust their speeds and movements to go through a discontinuity. Overall, the trajectory clustering method allowed us to observe sets of move- ments and summarize each cluster's components for comparison. This method can be applied to any area for similar analysis or for other purposes.

The results from this study confirm the importance of including discontinuity indicators in the planning and evaluation of cyclist network performances given the effect it has on cyclist behaviour. The lack of these indicators in current evaluation criteria provides a partial image of the quality of a cycling network and cycling experience and leaves transportation departments unable to address the effect of discontinuities on cyclists.

The challenges related to video data analysis include video recordings in windy conditions resulting in shaking in the video, and shadows of road users that are tracked as actual road users. Other challenges such as over-grouping and over-segmentation can be alleviated by optimizing tracking parameters. Classification errors are also observed and can be decreased by retraining and optimizing the classifier for the conditions encountered at the sites under study.

In addition, future work will focus on analyzing more sites to draw stronger conclusions. Cyclist behaviour will be analysed more comprehensively using more indicators and the safety of cyclists will be assessed using surrogate measures of safety. To confirm our findings on observed behaviour and gain better insight into the cyclists' underlying motivations, more locations should be studied with different methods such as surveying cyclists to obtain information on their perceived comfort at locations with discontinuities.

Acknowledgements: This research project is funded by the Fonds de Recherche du Québec - Nature et Technologies (FRQNT), grant 2015-NC-180344. The authors acknowledge the assistance of Anae Sobhani, Asad Lesani and Ting Fu for data collection. Finally, the authors thank the anonymous reviewers for their constructive comments.

\section{REFERENCES}

Aultman-Hall, L., \& Adams, M. (1998). Sidewalk Bicycling Safety Issues. Transportation Research Record, 1636(1), 71-76. https://doi.org/10.3141/1636-11

Aultman-Hall, L., Hall, F., \& Baetz, B. B. (1997). Analysis of Bicycle Commuter Routes Using Geographic Information Systems: Implications for Bicycle Planning. Transportation Research Record, 1578, 102-110. 
Bernardi, S., \& Rupi, F. (2015). An analysis of bicycle travel speed and disturbances on off-street and on-street facilities. Transportation Research Procedia. https://doi.org/10.1016/j. trpro.2015.01.004

Bíl, M., Andrášik, R., \& Kubeček, J. (2015). How Comfortable are Your Cycling Tracks? A New Method for Objective Bicycle Vibration Measurement. Transportation Research Part C: Emerging Technologies, 56, 415-425. https://doi.org/10.1016/j. trc.2015.05.007

Blanc, B., \& Figliozzi, M. (2016). Modeling the impacts of facility type, trip characteristics, and trip stressors on cyclists' comfort levels utilizing crowdsourced data. 95th Annual Meeting of The Transportation Research Board.

Broach, J., Dill, J., \& Gliebe, J. (2012). Where do cyclists ride? A route choice model developed with revealed preference GPS data. Transportation Research Part A: Policy and Practice, 46(10), 1730-1740. https://doi.org/10.1016/j. tra.2012.07.005

Brochure Dutch Cyclists' Association. (2003). Analysis of the problem of barrier formation. Retrieved from http://www.fietsberaad.nl/?lang=en\&repository $=$ Analysis + of + the + problem + of +barrier+forming

Copenhagenize Design Co. (2013). The choreography of an urban intersection. Retrieved June 20, 2016, from http://www. copenhagenize.com/2013/06/the-choreography-of-urban-intersection_14.html

CROW Fietsberaad. (n.d.). Bicycle tunnel under urban intersection. Retrieved from http://www.fietsberaad.nl/?section= $\underline{\text { Voorbeeldenbank\&lang=en\&mode }=\text { detail\&ontwerpvoorbe }}$ $\underline{\text { eldPage }=\& \text { repository }=\text { Bicycle }+ \text { tunnel }+ \text { under }+ \text { urban }+ \text { inter }}$ section

Dill, J., \& Gliebe, J. (2008). Understanding and measuring bicycling behavior: A focus on travel time and route choice. Center for Urban Studies/Center for Transportation Studies Portland State University. https://doi.org/http://www.royalcommission. vic.gov.au/finaldocuments/summary/PF/VBRC_Summary_ $\underline{\text { PF.pdf }}$

Foster, N., Dill, J., \& Clifton, K. (2015). A Level-of-Service Model for Protected Bike Lanes. Civil and Environmental Engineering Faculty Publications and Presentations, (304). Retrieved from http://pdxscholar.library.pdx.edu/cengin_ $\underline{\text { fac/304\%0AThis }}$

Garrard, J., Rose, G., \& Lo, S. K. (2008). Promoting Transportation Cycling for Women: The Role of Bicycle Infrastructure. Preventive Medicine, 46(1), 55-59. https://doi.org/10.1016/j. ypmed.2007.07.010

Geller, R. (2009). Four Types of Cyclists. Portland Office of Transportation. Portland, Oregon. Retrieved from https://www.portlandoregon.gov/transportation/44597? a $=237507$

Goodno, M., McNeil, N., Parks, J., \& Dock, S. (2013). Evaluation of Innovative Bicycle Facilities in Washington, D.C. Transportation Research Record: Journal of the Transportation Research Board, (2387), 139-148. https://doi.org/10.3141/2387-16

Harkey, D. et al. (1998). Development of the bicycle compatibility index: A level of service concept. Final Report, University of North Carolina, North Carolina.
Hölzel, C., Höchtl, F., \& Senner, V. (2012). Cycling comfort on different road surfaces. 9th Conference of the International Sports Engineering Association (ISEA), 34, 479-484. https:// doi.org/10.1016/j.proeng.2012.04.082

Hunt, J. D., \& Abraham, J. E. (2007). Influences on bicycle use. Transportation, 34, 453-470. https://doi.org/10.1007/s11116006-9109-1

Ismail, K., Sayed, T., Saunier, N., \& Lim, C. (2010). Automated analysis of pedestrian-vehicle conflicts using video data. Transportation Research Record: Journal of the Transportation Research Board, 2140(5), 52-64. https://doi. org/10.3141/2198-07

Jackson, S., Miranda-Moreno, L. F., St-Aubin, P., \& Saunier, N. (2013). A Flexible, Mobile Video Camera System and Open Source Video Analysis Software for Road Safety and Behavioural Analysis. 92nd Annual Meeting of the Transportation Research Board. Washington D.C. https://doi. org/10.3141/2365-12

Jensen, S., Rosenkilde, C., \& Jensen, N. (2007). Road safety and perceived risk of cycle facilities in Copenhagen. Presentation to AGM of European Cyclists Federation.

Kang, L., \& Fricker, J. D. (2013). Bicyclist commuters' choice of on-street versus off-street route segments. Transportation, 40(5), 887-902. https://doi.org/10.1007/s11116-013-9453-X

Krizek, K. J., \& Roland, R. W. (2005). What is at the end of the road? Understanding discontinuities of on-street bicycle lanes in urban settings. Transportation Research Part D: Transport and Environment, 10(1), 55-68. https://doi.org/10.1016/j. $\underline{\operatorname{trd} .2004 .09 .005}$

Landis, B. W. (1994). Bicycle interaction hazard score: A theoretical model. Transportation Research Record, (1438), 3-8. Retrieved from http://www.scopus.com/inward/record.url?eid=2$\underline{\text { s2.0-0028529542\&partnerID }=40 \& \mathrm{md} 5=7045 \mathrm{a} 21 \mathrm{e} 1572 \mathrm{f} 80 \mathrm{a} 3}$ c10d462839175e3

Laureshyn, A., Goede, M. De, Saunier, N., \& Fyhri, A. (2017). Cross-comparison of three surrogate safety methods to diagnose cyclist safety problems at intersections in Norway. Accident Analysis and Prevention, 105, 11-20. https://doi.org/10.1016/j. aap.2016.04.035

Li, B., Xiong, S., Li, X., Liu, M., \& Zhang, X. (2015). The behavior analysis of pedestrian-cyclist interaction at non-signalized intersection on campus: Conflict and interference. Procedia Manufacturing, 3, 3345-3352. https://doi.org/10.1016/j. promfg.2015.07.495

Lusk, A. C., Morency, P., Miranda-Moreno, L. F., Willett, W. C., \& Dennerlein, J. T. (2013). Bicycle guidelines and crash rates on cycle tracks in the United States. American Journal of Public Health, 103(7), 1240-1248. https://doi.org/10.2105/ AJPH.2012.301043

Ma, X., \& Luo, D. (2016). Modeling cyclist acceleration process for bicycle traffic simulation using naturalistic data. Transportation Research Part F: Psychology and Behaviour, 40, 130-144. https://doi.org/10.1016/j.trf.2016.04.009

Mekuria, M. C., Furth, P. G., \& Nixon, H. (2012). Low-stress bicycling and network connectivity. Final Report for the Mineta Transportation Institute. San José State University. 
Mereu, A. (2015). Analyzing the behavior of cyclists at intersections to improve behavior variability within micro-simulation traffic models. Masters Thesis for the Department of Civil Engineering, University of Waterloo. Waterloo, Ontario, Canada.

Mohamed, M. G., \& Saunier, N. (2015). Behaviour analysis using a multi-level motion pattern learning framework. 94th Annual Meeting of the Transportation Research Board, 15-6018. https://doi.org/10.3141/2528-13

Morris, B. T., \& Trivedi, M. M. (2008). A survey of vision-Based Trajectory Learning and Analysis for Surveillance. IEEE Transactions on Circuits and Systems for Video Technology, 18(8), 1114-1127. https://doi.org/10.1109/TCSVT.2008.927109

Morris, B., \& Trivedi, M. (2009). Learning Trajectory Patterns by Clustering: Experimental Studies and Comparative Evaluation. 2009 IEEE Computer Society Conference on Computer Vision and Pattern Recognition Workshops, CVPR Workshops 2009, 312-319. https://doi.org/10.1109/ CVPRW.2009.5206559

Nabavi-Niaki, M. S., Saunier, N., \& Miranda-Moreno, L. F. (2016). Methodology to quantify discontinuities in a cycling network - case study in Montreal boroughs. 95th Annual Meeting of The Transportation Research Board. https://doi.org/10.1017/ CBO9781107415324.004

NHTSA, \& National Household Traffic Survey of America. (2013). Traffic safety facts 2011 data. U.S. Department of Transportation, National Highway Traffic Safety Administration. https://doi.org/DOT HS 811743

Nosal, T., \& Miranda-Moreno, L. F. (2014). The effect of weather on the use of North American bicycle facilities: A multi-city analysis using automatic counts. Transportation Research Part A: Policy and Practice, 66, 213-225. https://doi.org/10.1016/j. tra.2014.04.012

Pucher, J., \& Buehler, R. (2006). Why Canadians cycle more than Americans: A comparative analysis of bicycling trends and policies. Transport Policy, 13, 265-279. https://doi. org/10.1016/j.tranpol.2005.11.001

Saunier, N., \& Sayed, T. (2006). Vehicle Trajectories Clustering with Dynamic Bayesian Networks for Traffic Safety Analysis. In Intelligent Transportation Systems (ITS) Canada Annual Conference. Whistler, BC, Canada. Retrieved from http://n.saunier. free.fr/saunier/stock/saunier07automated.pdf

Saunier, N., Sayed, T., \& Lim, C. (2007). Probabilistic collision prediction for vision-based automated road safety analysis. IEEE Conference on Intelligent Transportation Systems, Proceedings, ITSC, 872-878. https://doi.org/10.1109/ $\underline{\text { ITSC.2007.4357793 }}$

Sener, I. N., Eluru, N., \& Bhat, C. R. (2009). An analysis of bicycle route choice preferences in Texas, US. Transportation, 36(5), 511-539. https://doi.org/10.1007/s11116-009-9201-4

Sorton, A., \& Walsh., T. (1994). Bicycle stress level as a tool to evaluate urban and suburban bicycle compatibility. Transportation Research Record: Journal of the Transportation Research Board, (1438), 17-24.
Srisurapanon, V., Tangtrongchit, M. P., Ard-Onk, K., Limsuttiruch, P., Kiatpanachart, K., \& Luengsirinapha, P. (2003). Potential network for the improvement of bikeway in Bangkok. Proceedings of the Eastern Asia Society for Transportation Studies, 4(1-2), 1797-1807.

Stinson, M., \& Bhat, C. R. (2003). Commuter bicyclist route choice: Analysis using a stated preference survey. Transportation Research Record: Journal of the Transportation Research Board, 1828, 107-115. https://doi.org/10.3141/1828-13

Twaddle, H. (2017). Development of tactical and operational behaviour models for bicyclists based on automated video data analysis. Technical University of Munich.

Twaddle, H., Schendzielorz, T., \& Fakler, O. (2014). Bicycles in urban areas: Review of existing methods for modeling behavior. Transportation Research Record: Journal of the Transportation Research Board, (2434), pp 140-146. https://doi. org/10.3141/2434-17

U.S. Department of Transportation. (2001). Summary of travel trends 2001 National Household Travel Survey. Federal Highway Administration.

Vlakveld, W. P., Twisk, D., Christoph, M., Boele, M., Sikkema, R., Remy, R., \& Schwab, A. L. (2015). Speed choice and mental workload of elderly cyclists on e-bikes in simple and complex traffic situations: A field experiment. Accident Analysis and Prevention, 74, 97-106. https://doi.org/10.1016/j. aap.2014.10.018

Wardman, M., Tight, M., \& Page, M. (2007). Factors influencing the propensity to cycle to work. Transportation $R e$ search Part A: Policy and Practice, 41(4), 339-350. https://doi. org/10.1016/j.tra.2006.09.011

Willis, D. P., Manaugh, K., \& El-Geneidy, A. (2013). Uniquely satisfied: Exploring cyclist satisfaction. Transportation Research Part F: Traffic Psychology and Behaviour, 18, 136-147. https://doi.org/10.1016/j.trf.2012.12.004

Winters, M., Teschke, K., Grant, M., Setton, E. M., \& Brauer, M. (2010). How Far Out of the Way Will We Travel? Built Environment Influences on Route Selection for Bicycle and Car Travel. Transportation Research Record, 2190, 1-10.

Xie, F., \& Levinson, D. (2007). Measuring the structure of road networks. Geographical Analysis, 39(3), 336-356. https://doi. org/10.1111/j.1538-4632.2007.00707.x

Yang, C., \& Mesbah, M. (2013). Route choice behaviour of cyclists by stated preference and revealed preference. Australasian Transport Research Forum 2013 Proceedings, (October). Retrieved from http://atrf.info/papers/2013/2013_yang_ mesbah.pdf

Zaki, M. H., Sayed, T., \& Cheung, A. (2013). Computer vision techniques for the automated collection of cyclist data. Transportation Research Record: Journal of the Transportation Research Board, 2387, 10-19. https://doi.org/10.3141/2387-02

Zangenehpour, S., Miranda-Moreno, L. F., \& Saunier, N. (2013). Impact of bicycle boxes on safety of cyclists: A case study in Montreal. 92nd Annual Meeting of the Transportation Research Board. Washington D.C. 
Zangenehpour, S., Miranda-Moreno, L. F., \& Saunier, N. (2015). Automated classification based on video data at intersections with heavy pedestrian and bicycle traffic: Methodology and application. Transportation Research Part C: Emerging Technologies, 56, 161-176. https://doi.org/10.1016/j. trc.2015.04.003

Zangenehpour, S., Strauss, J., Miranda-Moreno, L. F., \& Saunier, N. (2016). Are signalized intersections with cycle tracks safer? A case-control study based on automated surrogate safety analysis using video data. Accident Analysis and Prevention, 86, 161-172. https://doi.org/10.1016/j.aap.2015.10.025 